\section{IS TARDIVE DYSKINESIA COMMONER IN JEWS?}

DEAR SIR,

Torsion dystonia has been found with higher prevalence among Jewish patients of Eastern European extraction (Eldridge, 1970; Korczyn et al, 1980), which prompted us to study the prevalence of another disorder of movement, tardive dyskinesia, according to Jewish or non-Jewish ethnic origin. Among 341 patients on neuroleptics we found 74 ( 22 per cent) of Jewish background. Of these, 42 (57 per cent) had tardive dyskinesia using the AIMS Scale, compared with 70 (30 per cent) of the non-Jewish patients, a highly significant difference (chi square 18.6, $P<0.001)$. There were no differences between the populations in age or current dose; all had been on neuroleptics for more than 10 years.

Further research on possible constitutional or hereditary factors in movement disorders would be very interesting.

R. YASSA

G. SCHWARTZ

Douglas Hospital, 6875 Lassalle Blvd., Verdun, Quebec H4H IR3

\section{References}

ElDRIDGE, R. (1970) The torsion dystonias: literature review and genetic and clinical studies. Neurology 20, 57-78.

Korczyn, A. D., et al (1980) Idiopathic torsion dystonia among Jewish ethnic groups. Neurology 30, 438.

\section{DOING WITHOUT ECT}

DeAR SIR,

My experience working at the Provincial Psychiatric Hospital of Tenerife (Spain), a 700 bedded hospital with a high admission rate, coincides with the experience of Drs Josephine and David Ben-Tovim (Brit. J. Psychiat. July 1982, 141, 102). At our hospital ECT has not been used for the past five years mainly for ethical reasons and we have found that depressed patients can be treated as effectively using a pharmacological and psychotherapeutical approach.

A. Garcia-Estrada Pérez

Excma. Mancomunidad Provincial Interinsular, De Santa Cruz De Tenerife, Hospital Psiquiatrico Provincial 